\title{
A method for the construction of in frame substitutions in operons: Deletion of the essential Escherichia coli holB gene coding for a subunit of the DNA polymerase III holoenzyme
}

\author{
David-Nicolas Chaperon * \\ Département de Biochimie Médicale, Centre Médical Universitaire, 1, rue Michel-Servet, CH-1211 Genève-4, Switzerland
}

Received 7 April 2005; received in revised form 29 June 2005; accepted 29 June 2005

Available online 9 August 2005

\begin{abstract}
To investigate the putative five-gene operon at $24.9 \mathrm{~min}$ on the Escherichia coli genome, which comprises the genes pabC, $y c e G, t m k, h o l B$ and $y c f H$, a method for the construction of an in frame deletion strain of the essential $E$. coli holB gene was developed. HolB, also referred to as delta prime or $\delta^{\prime}$, is a subunit of the DNA polymerase III (Pol III) holoenzyme. The holB gene was replaced by the kanamycin resistance gene $k k a l$, coding for amino glycoside $3^{\prime}$-phosphotransferase kanamycin kinase. The kanamycin resistance gene was expressed under the control of the promoter(s) of the putative five-gene operon. The $h o l B$ gene is essential for bacterial growth and the deletion of holB exhibits no polar effects on the adjacent genes tmk or $y c f H$ in terms of cell viability. The method of the holB null construction presented in this work allows for a simplified studying of interactions between the different subunits of DNA polymerase III.
\end{abstract}

(C) 2005 Elsevier B.V. All rights reserved.

Keywords: Co-transduction; DNA polymerase III; Gene substitution in operons; holB; In frame deletion

\section{Introduction}

The E. coli holB gene product designated HolB, delta prime or $\delta^{\prime}$, is a subunit of the E. coli DNA polymerase III. The DNA polymerase III (Pol III) holoenzyme is essential for bacterial growth and is highly processive. It is responsible for the major part

\footnotetext{
* Present address: Max-Planck-Institute for Biophysical Chemistry, Department of Molecular Genetics, Am Fassberg 11, D-37077 Göttingen, Germany. Tel.: +49 551201 1599; fax: +49 5512011718 .

E-mail address: David.Chaperon@medecine.unige.ch.
}

of DNA synthesis during the replication of the E. coli chromosome and is composed of at least 10 subunits $\left(\alpha, \varepsilon, \theta, \tau, \gamma, \delta, \delta^{\prime}, \chi, \psi\right.$, and $\left.\beta\right)$ (Kornberg and Baker, 1991; McHenry, 2003). HolB is thought to stimulate the DNA-dependent ATPase activity in the so-called clamp loading complex (Carter et al., 1993; O’Donnell et al., 2001; Onrust and O'Donnell, 1993). However, in vitro studies showed that replication activity can be reconstructed without HolB. HolB is supposed to stimulate the assembly of the subunits of the DNA polymerase and to increase the ATPase activity of the $\gamma$ complex (Onrust et al., 1991). Recent results indi- 
cate an essential role of HolB in DNA synthesis (Song et al., 2001).

The holB gene is located downstream of the tmk gene, coding for thymidylate kinase at $24.9 \mathrm{~min}$ on the $E$. coli chromosome. The holB gene was first identified using a reverse genetic approach (Carter et al., 1993) and found to be 1002 nucleotides long. Sequencing data showed a ribosomal binding site (RBS), a putative promoter site, and overlap of the $h o l B$ structural gene and the tmk gene. The holB gene codes for a $36.9 \mathrm{kDa}$ protein and its mRNA shows a rare codon usage, indicating a low HolB overexpression level (Konigsberg and Godson, 1983). Two HolB variants of similar protein mass appear on SDS-PAGE when detected with antibodies against the holoenzyme of DNA polymerase III (Dong et al., 1993). HolB has sequence similarity to other prokaryotic HolB proteins, to the dnaX gene products of E. coli (Dong et al., 1993; Flower and McHenry, 1986), to the replication factor $\mathrm{C}$ of HeLa cells (Chen et al., 1992), and to the gene 44 product of bacteriophage T4 (Spicer et al., 1984). Although the homology to the last two proteins is rather low, they are all involved in DNA replication.

In this work, a method for the construction of a holB deletion strain was established in which the holB gene has been replaced by the kanamycin resistance gene $k k a 1$. Co-transduction experiments indicate that $h o l B$ is essential for growth of $E$. coli. No polarity effects on viability due to the deletion construct were observed under the conditions tested. The holB deletion construct presented in this report allows a simplified studying of interactions of the components of the clamp loading complex, or of holB homologues from other organisms. This article describes a method of gene substitutions in operons in the presence of a plasmid-encoded gene, facilitating the introduction of selectable markers in essential genes for complementation experiments.

\section{Materials and methods}

\subsection{Bacterial strains, plasmids and phages, media and culture conditions}

The bacterial strains, plasmids, and phages used and constructed during the course of this study are listed in Table 1. LB medium containing $10 \mathrm{~g}$ of tryptone, $5 \mathrm{~g}$ of yeast extract and $5 \mathrm{~g}$ of $\mathrm{NaCl}$ per liter, $\mathrm{pH}$ 7.0, was used for bacterial growth. For LB agar plates, $10 \mathrm{~g}$ of agar was added per liter of medium. For selection of antibiotic resistance in liquid and solid medium, $100 \mu \mathrm{g} / \mathrm{ml}$ ampicillin, 25 $\mu \mathrm{g} / \mathrm{ml}$ kanamycin, $10 \mu \mathrm{g} / \mathrm{ml}$ chloramphenicol and $10 \mu \mathrm{g} / \mathrm{ml}$ tetracycline were used. Cells were grown at $37{ }^{\circ} \mathrm{C}$ with the exception of strains harboring the insertion $y c e G:: \operatorname{miniTn} 10\left(\operatorname{Kan}^{\mathrm{r}}\right)$ or when otherwise indicated.

\subsection{PCR, oligonucleotides and plasmid construction}

Polymerase chain reactions were performed with $P f u$ DNA polymerase according to the manufacturer's protocol (Promega, Madison, WI, USA). The plasmid pSR1613 (Table 1) served as template in the PCR reactions and for the amplification of the kanamycin resistance gene $k k a l$, the plasmid pACYC177 was used. The PCR fragment used in linear DNA transformation was obtained using plasmid $\mathrm{pDC} 10$ as template.

DNA sequences of PCR primers used in this work: Primer 1 (N-tmk $\left.5^{\prime} \rightarrow 3^{\prime}\right)$ : $5^{\prime}$-GGAGGAATTCACCATGCGCAGTAAGTATATCGT-3', primer 2 (C-tmk $\left.3^{\prime} \rightarrow 5^{\prime}\right): \quad 5^{\prime}$-ACGCGCATGCTCATGCGTCCAACTCCTTC-3', primer $3\left(\mathrm{~N}-\right.$ holB $\left.5^{\prime} \rightarrow 3^{\prime}\right)$ : $5^{\prime}$-GGAGGAATTCACCATGAGATGGTATCCATGGTTA-3', primer $4\left(\mathrm{C}-\right.$ holB $\left.3^{\prime} \rightarrow 5^{\prime}\right)$ : 5' -ACGCGCATGCTTAAAGATGAGGAACCG GTA-3', primer 5 ( $5^{\prime}$ of the operon): $5^{\prime}$-GTAGTGGCGGGCGAGG-3', primer 6 $\left(\mathrm{N}-t m k 3^{\prime} \rightarrow 5^{\prime}\right.$ ): 5' -ATCTGCATGCTTCCAGCCCCTCAATG-3', primer 7 (C-tmk $\left.5^{\prime} \rightarrow 3^{\prime}\right)$ : $5^{\prime}$-ATCTGCATGCTGGGTGAAGGAGTTGG- ${ }^{\prime}$, primer 8 (SalI $\left.y c f H 3^{\prime} \rightarrow 5^{\prime}\right): 5^{\prime}$-GCCAGAACGTCATCCACGTC-3', primer $9 \quad\left(\mathrm{~N}\right.$-holB $\left.\quad 3^{\prime} \rightarrow 5^{\prime}\right)$ : $\quad 5^{\prime}$-ATCTGCATGCTCTCATGCGTCCAACTC-3' ${ }^{\prime}$, primer 10 (C-holB $\left.5^{\prime} \rightarrow 3^{\prime}\right): 5^{\prime}$-ATCTGCATGCCTTTAAGAGAGACATCATGTTTT-3' ${ }^{\prime}$, primer 11 (universal primer): $5^{\prime}$-TAATACGCTCACTATAGGG-3', ${ }^{\prime}$, primer 12 (N-Kan $\left.5^{\prime} \rightarrow 3^{\prime}\right): \quad 5^{\prime}$-ATCTGCATGCTAAGTTATGAGCCATATTCAAC-3', primer 13 (C-Kan $3^{\prime} \rightarrow 5^{\prime}$ ): $5^{\prime}$-ATCTGCATGCCATTTAGAAAAACTCATCGAGCA-3', primer $14\left(\mathrm{C}-y c e G 5^{\prime} \rightarrow 3^{\prime}\right)$ : 5'-ATCTGCATGCCCAGGTGCGATAGCGA-3' ${ }^{\prime}$. Lyophilized primers synthesized by Invitrogen Ltd. (Paisley, UK) were dissolved in $\mathrm{H}_{2} \mathrm{O}$ and stored at $-20{ }^{\circ} \mathrm{C}$. 
Table 1

Strains, plasmids and phages used and constructed in this study

\begin{tabular}{|c|c|c|}
\hline Name & Description & Source/reference \\
\hline \multicolumn{3}{|l|}{ Strains } \\
\hline B178 & W3110 galEsup ${ }^{+}$ & $\begin{array}{l}\text { Georgopoulos, } \\
1971\end{array}$ \\
\hline DC1 & B178/入 & Gift of D. Ang \\
\hline DH5 $\alpha$ & $\begin{array}{l}F^{\prime} / \text { endA1 hsdR17 }\left(r_{K}^{-} m_{K}^{-}\right) \\
\text {glnV44 thi-1 recAl gyrA } \\
(\text { NalR }) \text { relA1 } \Delta(\text { laclZYA-argF }) \\
\text { U169 deoR }(\Phi 80 \text { dlac }(\text { lacZ }) M 15)\end{array}$ & $\begin{array}{l}\text { Woodcock et al., } \\
1989\end{array}$ \\
\hline DY378 & 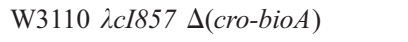 & $\mathrm{Yu}$ et al., 2000 \\
\hline SR749 & E. coli yce $G:: \operatorname{mini} \operatorname{Tn} 10\left(\operatorname{Kan}^{\mathrm{r}}\right)$ & Gift of S. Raina \\
\hline DC2 & $\begin{array}{l}\text { B178 miniTn10 }\left(\text { Tet }^{\mathrm{r}}\right) \text { linked } \\
\text { to holB }\end{array}$ & This work \\
\hline DC3 & $\begin{array}{l}\text { DY378, miniTn10 }\left(\text { Tet }^{\mathrm{r}}\right) \\
\text { linked to holB }\end{array}$ & This work \\
\hline DC4 & DC3 with pMPM-A6 $\Omega$ & This work \\
\hline DC5 & DC3 with pDC2 & This work \\
\hline DC6 & DC5, $\Delta$ holB::kkal & This work \\
\hline DC7 & $\begin{array}{l}\text { B178, } \Delta \text { holB, with pDC2, } \\
\text { Tet }^{\mathrm{r}}, \mathrm{Kan}^{\mathrm{r}}\end{array}$ & This work \\
\hline
\end{tabular}

Plasmids

\begin{tabular}{|c|c|c|}
\hline pACYC177 & $\begin{array}{l}\mathrm{Amp}^{\mathrm{r}}, \mathrm{Kan}^{\mathrm{r}}, \text { low copy } \\
\text { p15A origin }\end{array}$ & $\begin{array}{l}\text { Chang and } \\
\text { Cohen, } 1978\end{array}$ \\
\hline pKO3 & $\begin{array}{l}\mathrm{Cm}^{\mathrm{r}} \text {, low copy } p S C 101 \mathrm{Ts} \\
\text { origin, } s a c B\end{array}$ & $\begin{array}{l}\text { Link et al., } \\
1997\end{array}$ \\
\hline pMPM-A $6 \Omega$ & $\mathrm{Amp}^{\mathrm{r}}$, low copy $p 15 \mathrm{~A}$ origin & Mayer, 1995 \\
\hline pSR1613 & $\begin{array}{l}\text { pWSK29 with a } 7.1 \mathrm{~kb} \text { DNA } \\
\text { fragment at } 24.9 \mathrm{~min} \text { on } \\
\text { the } E \text {. coli genome }\end{array}$ & Gift of S. Raina \\
\hline pWSK29 & $\mathrm{Amp}^{\mathrm{r}}$, low copy $p S C 101$ origin & $\begin{array}{l}\text { Wang and } \\
\text { Kushner, } 1991\end{array}$ \\
\hline $\mathrm{pDC} 1$ & $\begin{array}{l}\text { pWSK29, pabC, yceG, tmk, } \\
\text { holB, ycfH }\end{array}$ & This work \\
\hline $\mathrm{pDC} 2$ & pMPM-A $6 \Omega$, holB & This work \\
\hline pDC3 & pMPM-A6 $\Omega, t m k$ & This work \\
\hline $\mathrm{pDC} 4$ & pMPM-A $6 \Omega, t m k$ and holB & This work \\
\hline pDC5 & $\begin{array}{l}\text { pMPM-A } 6 \Omega, t m k, h o l B \\
\text { and } y c f H\end{array}$ & This work \\
\hline pDC6 & $\mathrm{pDC} 1, \mathrm{tmk}$ in frame deletion & This work \\
\hline $\mathrm{pDC} 7$ & pKO3, pabC, yceG, holB, ycfH & This work \\
\hline pDC8 & $\begin{array}{l}\text { pWSK29, pabC, yceG, } \\
\text { tmk and } y c f H\end{array}$ & This work \\
\hline pDC9 & $\begin{array}{l}\mathrm{pKO} 3, p a b C, y c e G \\
\text { tmk and } y c f H\end{array}$ & This work \\
\hline $\mathrm{pDC} 10$ & pDC9, kkal in $S p h \mathrm{I}$ & This work \\
\hline \multicolumn{3}{|l|}{ Phages } \\
\hline P1vir & $\begin{array}{l}\text { Bacteriophage P1 for } \\
\text { transductions }\end{array}$ & Our collection \\
\hline$\lambda 1098$ & $\lambda$ hop miniTn $10\left(\mathrm{Tet}^{\mathrm{r}}\right)$ & Way et al., 1984 \\
\hline
\end{tabular}

General techniques for plasmid DNA preparation, restriction enzyme manipulation, molecular cloning, and agarose gel electrophoresis were carried out by standard protocols. Restriction endonucleases and enzymes for DNA modification were purchased from New England Biolabs (Beverly, MA, USA) and Boehringer Mannheim (Roche Diagnostics, Germany). Transformations and plasmid preparations were done in DH5 $\alpha$ (Woodcock et al., 1989). The plasmid pSR1613, a pWSK29-based low copy number vector (Wang and Kushner, 1991), contains a 7.1 $\mathrm{kb}$ fragment spanning the region at $24.9 \mathrm{~min}$ on the E. coli genome (gift of S. Raina). Cloning of the $B g l$ II/HindIII fragment of pSR1613 into the unique Bam HI/HindIII sites of pWSK29 created plasmid pDC1. The plasmids pDC2, pDC3 and pDC4 were generated by insertion of the EcoRI- and SphIdigested PCR products resulting from amplification using the primer pairs 1 and 2, 3 and 4, and 1 and 4, respectively, into the EcoRI/SphI-digested, arabinose-inducible vector pMPM-A6 $\Omega$ (Mayer, 1995). Plasmid pDC5 was engineered by the insertion of the NheI/HindIII fragment harboring $y c f H$ of the plasmid pDC1 into the NheI/HindIII-digested plasmid pDC4, expressing tmk, holB and ycfH under the arabinose-inducible $p B A D$ promoter. Plasmid pDC6 was constructed by ligation of the PCR fragments obtained with the primers 5 and 6 (digested with Aat II/SphI) and primers 7 and 8 (digested with $S p h \mathrm{I} /$ NheI) into the Aat II/NheI-digested plasmid pDC1. The $B g l \mathrm{II} / X h o \mathrm{I}$ fragment containing the tmk deletion construct of pDC6 was inserted into the Bam HI/ SalI-digested vector pKO3 (Link et al., 1997) resulting in plasmid pDC7. Plasmid pDC8 was constructed by ligation of the PCR products of primers 5 and $9(X h o \mathrm{I} / S p h \mathrm{I})$ and primers 10 and 11 (universal primer) (KpnI/SphI) into pDC1, digested with $K p n \mathrm{I}$ and XhoI. Plasmid pDC9 resulted from the insertion of the RsrII/AseI fragment of pDC8 into the RsrII/AseI-digested plasmid pDC7. Plasmid pDC9 contains a 2100 bp homology region at the $5^{\prime}$ end of the $h o l B$ gene and $700 \mathrm{bp}$ at the 3' end around the holB deletion. Plasmid pDC10 was constructed by introducing the $S p h \mathrm{I}$ digested PCR product (kanamycin resistance gene kkal) of pACYC177 (primers 12 and 13) into the unique SphI site of plasmid pDC9, followed by selection for $\mathrm{Kan}^{\mathrm{r}}$. 


\subsection{MiniTn10 tetracycline resistance (Tet $\left.{ }^{r}\right)$ marker linked to holB}

Preparations of bacteriophage P1-lysates and transductions were performed as described (Miller, 1972). A Tet ${ }^{\mathrm{r}}$ marker linked to tmk was isolated using the $\lambda 1098$ bacteriophage (Way et al., 1984) to create a library of miniTn10 $\left(\mathrm{Tet}^{\mathrm{r}}\right)$ insertions in strain SR749 (yceG::miniTn10 $\left(\operatorname{Kan}^{\mathrm{r}}\right)$, gift of S. Raina), selecting for both $\mathrm{Tet}^{\mathrm{r}}$ and $\mathrm{Kan}^{\mathrm{r}}$ colonies. A P1-lysate was grown on the pooled library of $\operatorname{Tet}^{\mathrm{r}}$ and $\mathrm{Kan}^{\mathrm{r}}$ candidates of previously transduced SR749 and used to simultaneously transduce the two markers into DC1, strain B178 harboring a $\lambda$-prophage (B178/ $\lambda$, gift of D. Ang). Seven $\operatorname{Tet}^{\mathrm{r}}$ and $\mathrm{Kan}^{\mathrm{r}}$ transductants of DC1 were used for the preparation of P1-lysates and tested further to determine their co-transduction frequency. B178 was transduced with the lysates of the candidates, selecting first for $\mathrm{Kan}^{\mathrm{r}}$, followed by screening for Tet ${ }^{\mathrm{r}}$. This procedure resulted in strains with cotransduction frequencies between $6 \%$ and $72 \%$ (Tet $^{r}$ and $\mathrm{Kan}^{\mathrm{r}}$ ), which have both markers, a miniTn 10 $\left(\mathrm{Tet}^{\mathrm{r}}\right)$ insertion linked to holB and the $y c e G:: \mathrm{mi}-$ niTn10 $\left(\mathrm{Kan}^{\mathrm{r}}\right)$ marker. DC2 with a co-transduction frequency of about $40 \%$ was used for further experiments (Table 1, Fig. 1, data not shown).

\subsection{Construction of holB replacement deletion in the E. coli genome}

The deletion was done by linear transformation as described (Yu et al., 2000). As a first step, the strain DY378 was transduced at $30{ }^{\circ} \mathrm{C}$ with a P1-lysate grown on DC2 to introduce the miniTn10 $\left(\mathrm{Tet}^{\mathrm{r}}\right)$ marker next to holB. The resulting strain DC3 was further transformed at $30{ }^{\circ} \mathrm{C}$ with the plasmid pMPM-A6 $\Omega$
Table 2

Linear transformation for the construction of the $\Delta$ holB::kkal strain and co-transduction experiments

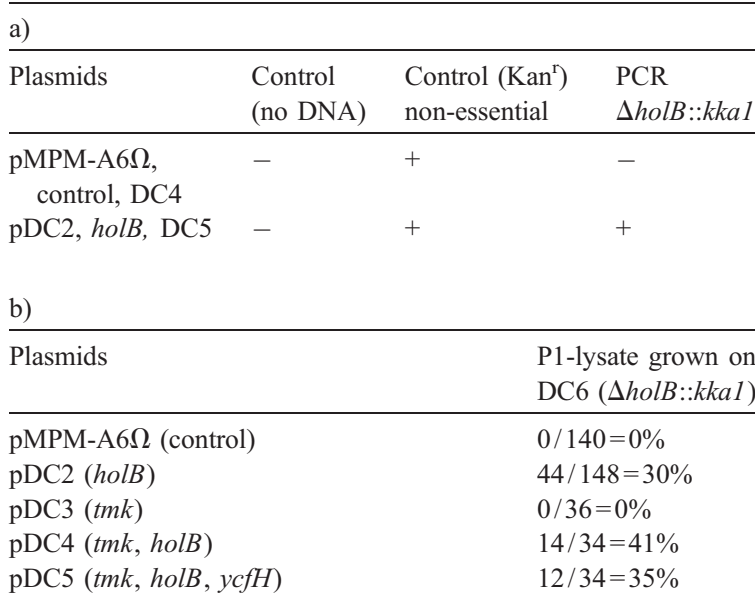

a) Transformation of strains DC4 and DC5 was performed without DNA, with PCR amplified DNA from a non-essential kanamycin resistance construct, or with the $1600 \mathrm{bp}$ PCR product from $\mathrm{pDC} 10$ $(\Delta h o l B:: k k a 1)$. DC4 is DC3 (DY378, miniTn10 $\left(\mathrm{Tet}^{\mathrm{r}}\right)$ linked to holB) transformed with pMPM-A6 $\Omega$ (control); DC5 is DC3 (DY378, miniTn10 $\left(\mathrm{Tet}^{\mathrm{r}}\right)$ linked to holB) transformed with pDC2 (arabinose-inducible second copy of holB). $(-)=$ no transformants, $(+)$ transformants. b) Co-transduction frequencies between $\Delta$ holB::kkal and the nearby miniTn $10\left(\operatorname{Tet}^{\mathrm{r}}\right)$ marker: B178 carrying various arabinose-inducible plasmids was co-transduced with a P1-lysate grown on DC6 $(\Delta h o l B:: k k a 1)$ in the presence of $0.05 \% \mathrm{~L}-$ arabinose at $30^{\circ} \mathrm{C}$. In general, about 40 colonies were tested in each experiment; higher numbers are total numbers of different experiments. Transductants were first selected for $\operatorname{Tet}^{r}$, followed by screening for both $\operatorname{Kan}^{\mathrm{r}}$ and Tet ${ }^{\mathrm{r}}$. Fractions indicate number of $\operatorname{Tet}^{\mathrm{r}}$ and $\mathrm{Kan}^{\mathrm{r}} /$ number of $\mathrm{Tet}^{\mathrm{r}}$ transductants, followed by the calculated co-transduction frequency in $\%$.

(control) and with pDC2 (holB) to give strains DC4 and DC5. PCR amplification of the kanamycin resistance construct $\Delta$ holB $:: k k a l$ was performed on plas-

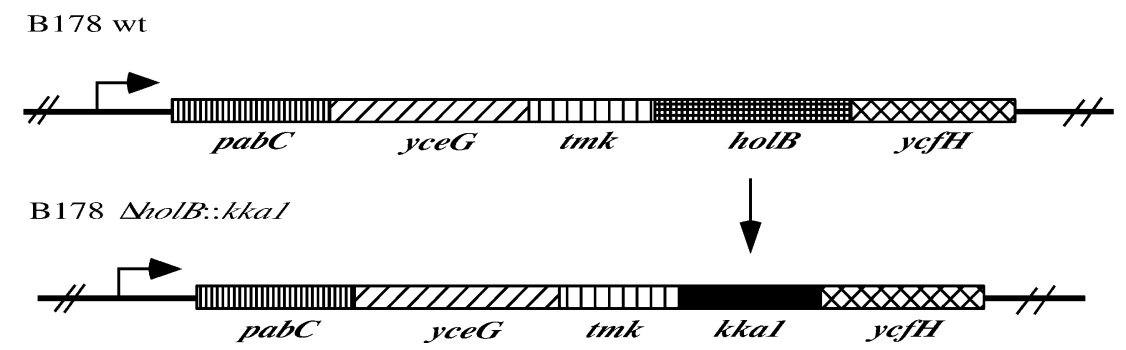

Fig. 1. Construction of the holB replacement strains: $p a b C=4$-amino-4-deoxy-chorismate lyase, $y c e G=$ gene of unknown function, $t m k=$ thymidylate kinase, $h o l B=$ subunit of DNA polymerase III, $y c f H=$ conserved gene of uncertain function, $k k a l=$ kanamycin resistance gene. 
mid pDC10 (primers 8 and 14). Besides the kanamycin resistance gene, the PCR product contains $600 \mathrm{bp}$ of DNA located upstream of holB and 100 bp of DNA located downstream. After digestion with $D p n I$, the purified PCR product was used for transformation of strains DC4 and DC5. As a control, no DNA or PCRamplified DNA from a non-essential kanamycin insertion strain was used (gift of P. Genevaux). Kanamycin resistant colonies were selected at $30{ }^{\circ} \mathrm{C}$ on LB agar plates containing ampicillin, kanamycin, tetracycline and $0.05 \% \mathrm{~L}$-arabinose. Table $2 \mathrm{a}$ shows data of the linear transformations of DC4 and DC5 depending on the DNA fragment used. This resulted in strain DC6.

\subsection{Co-transduction experiments}

A bacteriophage P1-lysate was grown on DC6 and was used to infect B178 harboring various plasmids. Transductants were first selected on LB agar plates containing $10 \mathrm{mM}$ sodium citrate, tetracycline, ampicillin and $0.05 \% \mathrm{~L}$-arabinose. In a second step, transductants were screened on LB-agar plates containing $10 \mathrm{mM}$ sodium citrate, kanamycin, tetracycline, ampicillin and $0.05 \% \mathrm{~L}$-arabinose to determine co-transduction frequency between the nearby marker $\left(\mathrm{Tet}^{\mathrm{r}}\right)$ and the deleted holB gene $\left(\mathrm{Kan}^{\mathrm{r}}\right)$. Co-transduction was only observed in the presence of a second plasmid-encoded holB gene (Table 2b). A Tet ${ }^{\mathrm{r}}$ and $\mathrm{Kan}^{\mathrm{r}}$ candidate of $\mathrm{B} 178$ transformed with $\mathrm{pDC} 2$ resulted in strain DC7.

\section{Results}

To generate a $\Delta$ holB::kkal E. coli strain, a set of plasmids was constructed as described in Table 1. The E. coli holB gene was replaced by the kanamycin resistance gene $k k a l$, which is expressed under the control of the promoter(s) of the putative five-gene operon (Fig. 1). The gene kkal was cloned into the unique SphI site of pDC9, the ligation transformed into DH5 $\alpha$ and selected for $\mathrm{Kan}^{\mathrm{r}}$. The resulting plasmid pDC10 expresses the kanamycin resistance from the promoter(s) of the five-gene operon. Thus, in the plasmid $\mathrm{pDC} 10$ and later in the E. coli chromosome, no additional ribosomal binding sites (RBS) (Shine and Dalgarno, 1974) for kkal and $y c f H$ were introduced (Fig. 2c and d).
The starting strain DY378 was transduced with the miniTn10 $\left(\mathrm{Tet}^{\mathrm{r}}\right)$ marker of strain DC2, resulting in strain DC3. The gene deletion experiment was performed with DC3 by linear transformation (Yu et al., 2000), using either the control plasmid pMPM-A6 $\Omega$ (DC4) or the arabinose-inducible plasmid pDC2 (DC5), carrying a second copy of the holB gene. The strains containing the nearby $\operatorname{Tet}^{\mathrm{r}}$ marker and a plasmid were then transformed with a linear DNA fragment that was obtained by PCR amplification of the kanamycin resistance gene insertion in holB present on plasmid pDC10. Additionally, negative (without DNA) and positive controls (non-essential $\mathrm{Kan}^{\mathrm{r}}$ insertion, gift of P. Genevaux) were performed. In the transformations with the positive control (non-essential $\mathrm{Kan}^{\mathrm{r}}$ insertion) (Table 2a), both strains, DC4 (pMPM-A6 $\Omega$, control) and DC5 (pDC2, arabinoseinducible holB gene), showed $\mathrm{Kan}^{\mathrm{r}}$ linear transformants (+). For the transformation of the PCR amplified insertion construct in holB, only $\mathrm{Kan}^{\mathrm{r}}$ linear transformants were observed for DC5 (pDC2, arabinose-inducible holB gene),(+), but not for DC4 (pMPM-A6 $\Omega$, control), (-). Without DNA, no transformants were observed $(-)$. The number of positive $(+)$ transformants varied from a few to several thousand colonies depending on the quality and amount of DNA, the electro-competent strains as well as the electroporation chambers used. However, no transformants were observed in cases indicated by $(-)$ in Table 2a.

This experiment showed that a plasmid-encoded copy of holB was required in order to delete holB, demonstrating an essential role of the HolB protein in cell growth (Table 2a). These experiments resulted in strain DC6. Since the plasmid pDC10 can also be used for genomic recombinations using the plasmid pK03 system (Link et al., 1997), another recombination experiment under similar conditions was performed, confirming the result that holB is an essential gene (data not shown).

A P1-lysate grown on strain DC6 was used to transduce strain B178, previously transformed with arabinose-inducible plasmids harboring different genes of the holB operon, pDC2 to pDC5 (see Table $1)$. This procedure allowed delineating whether it is possible to delete the holB gene, or whether the holB is essential for $E$. coli growth. If the holB gene can be deleted from the E. coli genome, then a co-transduc- 
RBS

a) 5'-tgggtgaaggagttggacgcATGAgatggtatccat-3'

C-terminus of Tmk

$$
\mathrm{N} \frac{}{\text { N-terminus of HolB }}
$$

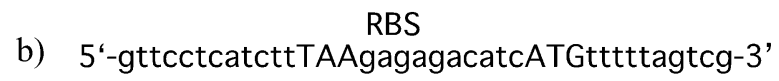

$$
\underset{\text { C-terminus of } \mathrm{HolB}}{\mathrm{N}} \longrightarrow
$$

RBS Sphl

c) 5'-tgggtgaaggagttggacgcATGAgagcATGccttTAAgttATGagccatattcaac-

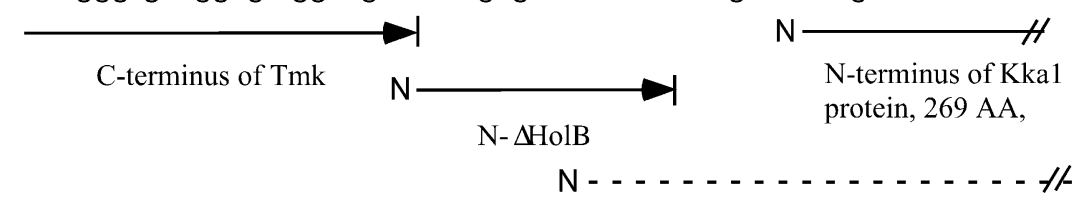

Potential 25 AA polypetide followed by

a stop codon in the $k k a l$ gene

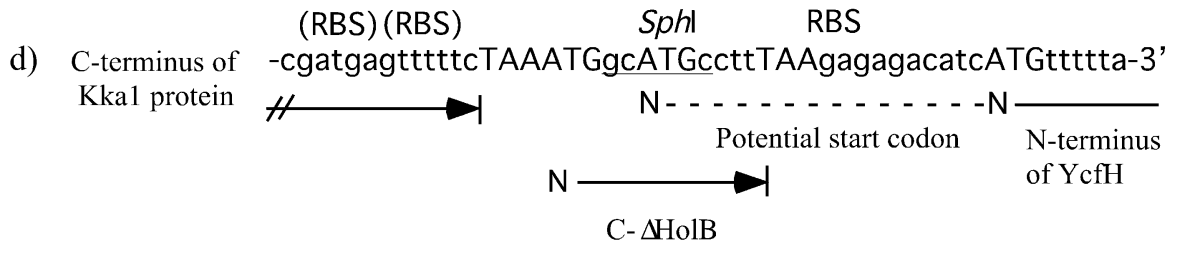

Fig. 2. Genomic sequence details at the 24.9 min region on the E. coli chromosome and translation products of the mRNA(s) at a) the Nterminus and $\mathrm{b}$ ) the $\mathrm{C}$-terminus of the HolB protein. DNA sequences of the $\Delta$ holB::kkal construct and its translational products at c) the $\mathrm{N}$ terminus and d) the C-terminus of the original holB translational product. Lines and arrows indicate translation products. Capital triplets represent start and stop codons. Dashed lines represent potential translational products. $S p h \mathrm{I}$ and underlined sequences=restriction site of $S p h \mathrm{I}$, $(\mathrm{RBS})=$ potential ribosomal binding site, $\mathrm{RBS}=$ ribosomal binding site derived from sequence analysis.

tion efficiency of about $40 \%$ is expected, since the closely linked yceG::miniTn10 (Kan $\left.{ }^{\mathrm{r}}\right)$ marker of SR749 exhibits a similar co-transduction frequency (data not shown). The results presented in Table $2 \mathrm{~b}$ clearly show that holB cannot be removed from the $E$. coli chromosome unless another copy of this gene is provided in trans, implying that holB gene is indispensable for $E$. coli viability. These data also suggest that the holB deletion does not exert a significant polarity effect on the neighboring genes, such as tmk or $y c f H$.

Strains carrying the $\Delta h o l B$ construct, such as DC7, were verified by various PCR amplification reactions using primers specific for the genome or for plasmids used for the construction of strains (data not shown). These PCR experiments indicate the correct substitution of the holB gene by the insertion of the kkal gene. In addition, Southern blot analyses confirmed that the $k k a l$ gene correctly replaces the holB gene in the $\Delta$ holB::kkal strains (data not shown).

\section{Discussion}

The rationale behind the replacement of holB by the kanamycin resistance gene kkal, coding for the 
amino glycoside $3^{\prime}$-phosphotransferase kanamycin kinase, was to almost completely eliminate the holB gene from the E. coli genome. This should be done in a way to introduce a selectable marker into $h o l B$, but to exclude polar effects on down-stream as well as on up-stream genes.

Two different approaches were tested for the introduction of the holB deletion and kkal replacement construct (Link et al., 1997; Yu et al., 2000). Both methods gave identical results, demonstrating an essential role of the HolB protein for E. coli viability. The genetic environment of the holB gene is relatively simple (Blattner et al., 1997), since there are no overlapping structural gene sequences, except for the start codon of the holB open reading frame (ORF) (Fig. 2a) and the stop codon of the tmk ORF (Fig. 2b). However, in the case of the up-stream gene tmk the genomic situation appears more complex (Chaperon, unpublished). The resulting genomic sequence regions of the $\Delta$ holB::kkal replacement construct are indicated in Fig. $2 \mathrm{c}$ and $\mathrm{d}$.

A PCR fragment of $1600 \mathrm{bp}$ amplified from plasmid pDC10 was used for linear transformation (Yu et al., 2000). $\mathrm{Kan}^{\mathrm{r}}$ colonies could be obtained only in the presence of an arabinose-inducible second copy of holB (pDC2) (Table 2a). When the $\Delta$ holB ::kkal strain was constructed by the method of the temperaturesensitive and negative-selectable plasmid pK03 (Link et al., 1997), an identical phenotype was observed. This finding was confirmed by co-transduction experiments, where double-resistant colonies were only seen in the presence of an arabinose-inducible second copy of holB (Table 2b). These results are in agreement with a holB conditional null strain (Song et al., 2001).

However, whereas the holB null construct of Song et al. (2001) contains a double-ochre mutation, the holB null mutant generated in the present work is nearly completely deleted. This has the advantage that recombination in-between the genomic substitution construct and plasmid-encoded holB genes can be excluded. Therefore, expressing holB from the arabinose-inducible plasmid $\mathrm{pDC} 2$, recombination with the genomic holB null allele can be excluded with high probability. Furthermore, using the idea of complete gene deletion/substitution, interactions of remaining protein fragments with complementing proteins or other proteins of the cell are not possible. The method described here allows experiments in any genetic background as long as HolB activity is provided from a plasmid in trans. Therefore, this method allows a simplified studying of essential genes of operons by complementation with a plasmid-encoded copy of a gene.

\section{Acknowledgements}

I thank Debbie Ang, Pierre Genevaux and Satish Raina for the gift of genetic material, and Manfred Konrad for discussions and help in editing the manuscript. This work was supported by grant FN 3165403 from the Swiss National Science Foundation (laboratory of Prof. C. Georgopoulos, Geneva, Switzerland) and the canton of Geneva, Switzerland.

\section{References}

Blattner, F.R., Plunkett III, G., Bloch, C.A., Perna, N.T., Burland, V., Riley, M., et al., 1997. The complete genome sequence of Escherichia coli K-12. Science 277, 1453-1474.

Carter, J.R., Franden, M.A., Aebersold, R., McHenry, C.S., 1993. Identification, isolation, and characterization of the structural gene encoding the delta' subunit of Escherichia coli DNA polymerase III holoenzyme. J. Bacteriol. 175, 3812-3822.

Chang, A.C., Cohen, S.N., 1978. Construction and characterization of amplifiable multicopy DNA cloning vehicles derived from the P15A cryptic miniplasmid. J. Bacteriol. 134, 1141-1156.

Chen, M., Pan, Z.Q., Hurwitz, J., 1992. Studies of the cloned 37kDA subunit of activator 1 (replication factor C) of HeLa cells. Proc. Natl. Acad. Sci. U. S. A. 89, 5211-5215.

Dong, Z., Onrust, R., Skangalis, M., O’Donnell, M., 1993. DNA polymerase III accessory proteins: I. holA and holB encoding delta and delta'. J. Biol. Chem. 268, 11758-11765.

Flower, A.M., McHenry, C.S., 1986. The adjacent dnaZ and dnaX genes of Escherichia coli are contained within one continuous open reading frame. Nucleic Acids Res. 14, 8091-8101.

Georgopoulos, C.P., 1971. Bacterial mutants in which the gene $N$ of bacteriophage lambda is blocked have an altered RNA polymerase. Proc. Natl. Acad. Sci. U. S. A. 68, 2977-2981.

Konigsberg, W., Godson, G.N., 1983. Evidence for use of rare codons in the dnaG gene and other regulatory genes of Escherichia coli. Proc. Natl. Acad. Sci. U. S. A. 80, 687-691.

Kornberg, A., Baker, T.A., 1991. DNA Replication, 2nd ed. WH Freeman, New York, USA.

Link, A.J., Phillips, D., Church, G.M., 1997. Methods for generating deletions and insertions in the genome of wild-type Escherichia coli: application to open reading frame characterization. J. Bacteriol. 179, 6228-6237.

Mayer, M.P., 1995. A new set of useful cloning and expression vectors derived from pBlueScript. Gene 163, 41-46. 
McHenry, C.S., 2003. Chromosomal replicases as asymmetric dimers: studies of subunit arrangement and functional consequences. Mol. Microbiol. 49, 1157-1165.

Miller, J.H., 1972. Experiments in Molecular Genetics. Cold Spring Harbor Laboratory Press, Cold Spring Harbor, NY, USA.

O’Donnell, M., Jeruzalmi, D., Kuriyan, J., 2001. Clamp loader structure predicts the architecture of DNA polymerase III holoenzyme and RFC. Curr. Biol. 11, R935-R946.

Onrust, R., O’Donnell, M., 1993. DNA polymerase III accessory proteins: II. characterization of delta and delta'. J. Biol. Chem. 268, 11766-11772.

Onrust, R., Stukenberg, P.T., O’Donnell, M., 1991. Analysis of the ATPase subassembly which initiates processive DNA synthesis by DNA polymerase. J. Biol. Chem. 266, 21681-21686.

Shine, J., Dalgarno, L., 1974. The 3'-terminal sequence of Escherichia coli $16 \mathrm{~S}$ ribosomal RNA: complementary to nonsense triplets and ribosome binding sites. Proc. Natl. Acad. Sci. U. S. A. $71,1342-1346$.

Song, M.S., Pham, P.T., Olson, M., Carter, J.R., Franden, M.A., Schaaper, R.M., et al., 2001. The delta and delta' subunits of the DNA polymerase III holoenzyme are essential for initiation complex formation and processive elongation. J. Biol. Chem 276, 35165-35175.

Spicer, E.K., Nossal, N.G., Williams, K.R., 1984. Bacteriophage T4 gene 44 DNA polymerase accessory protein. Sequences of gene 44 and its protein product. J. Biol. Chem. 259, 15425-15432.

Wang, R.F., Kushner, S.R., 1991. Construction of versatile lowcopy-number vectors for cloning, sequencing and gene expression in Escherichia coli. Gene 100, 195-199.

Way, J.C., Davis, M.A., Morisato, D., Roberts, D.E., Kleckner, N., 1984. New Tn10 derivatives for transposon mutagenesis and for construction of lacZ operon fusions by transposition. Gene 32, 369-379.

Woodcock, D.M., Crowther, P.J., Doherty, J., Jefferson, S., DeCruz, E., Noyer-Weidner, M., et al., 1989. Quantitative evaluation of Escherichia coli host strains for tolerance to cytosine methylation in plasmid and phage recombinants. Nucleic Acids Res. 17, 3469-3478.

Yu, D., Ellis, H.M., Lee, E.C., Jenkins, N.A., Copeland, N.G., Court, D.L., 2000. An efficient recombination system for chromosome engineering in Escherichia coli. Proc. Natl. Acad. Sci. U. S. A. $97,5978-5983$. 